\title{
Global Pollution and World Food Reserves
}

\author{
Jack T. Trevors
}

Published online: 13 October 2009

(C) Springer Science + Business Media B.V. 2009

The gap between the global food demands and the actual amounts of food and reserves is an international food security crisis. As the human population continues to increase, immense demands are placed on fossil fuels, soil fertility, water, air quality, farming equipment, technology, transportation, refrigeration, food processing, waste management, pest control, agricultural chemicals, seed varieties and labour, to name a few examples. All of these activities have one thing in common - they use energy and they generate local and global pollution. It is not a secret that trying to feed 6.6 billion humans requires immense inputs and produces immense global pollution. In less than 50 years, the number of humans will be about 12 billion if human population growth is not correctly managed on a global scale. One to two billion humans are currently malnourished and/or starving. To double these human numbers in the future is not logical, rational and/or possible without more immense human suffering and death.

Rice, wheat and corn feed the world. These three crops stand between humans and starvation. More than $90 \%$ of the world's food supply comes from the land. Oceans and freshwater supply very little of our actual food. To produce more grain crops, we need more fertile land and all the infrastructure to produce, harvest, store, process and transport the food globally. However, we must also consider the amount of fertile land taken out of production for urbanisation, erosion problems,

J. T. Trevors $(\bowtie)$

School of Environmental Sciences, University of Guelph, Guelph, ON, Canada N1G 2W1

e-mail: jtrevors@uoguelph.ca droughts and flooding. The pressure to place more forest soils into agricultural production leads to more deforestation. Add into the equation, rapid climate change and the situation becomes more complex.

The solutions are also complex and include immediate universal human population control funded by the wealthy nations, conservation, conservation and more conservation, renewable energy supplies, energy efficiency, transportation efficiency, education, education, and more education, universal human rights and needs, global public health infrastructure, agricultural research, local food reserves and a world food reserve. Even with these advances/solutions, there is no certainty that the outcome will be successful and sustainable. The present food crisis is inflicting pain, suffering and death on millions of humans. This is only a fraction of what will occur in the future as climate change, overpopulation and increasing oil prices merge to devastate many humans in many countries. To deny that there is a crisis and to be wishful that it can be solved by technology are not rational strategies. Moreover, humans who look to a supernatural entity to save them and also believe that reproduction should not be controlled should be aware that this is not a rational strategy. The interesting thing about supernatural entities is when humans stop believing in them, they disappear.

Agriculture is a major source of water, air and soil pollution as we all participate in agriculture in one way or another. Humans who can afford safe food are also privileged. Local, national and global food reserves should be part of a rational and logical plan to address the intersection of global climate change and human population growth. 